\author{
P. Löfgren · J. Hoffstedt • E. Näslund $\cdot$ M. Wirén • \\ P. Arner
}

\title{
Prospective and controlled studies of the actions of insulin and catecholamine in fat cells of obese women following weight reduction
}

Received: 25 May 2005 / Accepted: 4 July 2005 / Published online: 13 October 2005

(C) Springer-Verlag 2005

\begin{abstract}
Aims/hypothesis: Enlarged fat cells from obese subjects are characterised by insulin resistance and abnormal adrenergic regulation of lipolysis. The aim of the present study was to examine whether these aberrations return to normal following weight reduction. Materials and methods: Obese women $(n=25)$ were investigated before and $3 \pm 1$ years $($ mean \pm SD) after steady-state weight reduction and compared with control women who were matched to the cases at re-examination in terms of age and BMI. Adipocyte volume, lipogenesis and lipolysis were determined in isolated subcutaneous fat cells following stimulation or inhibition at different steps of the lipolytic cascade. Results: Weight reduction decreased fat cell volume and basal and adrenergic-regulated lipolysis rates to values that were $20-40 \%$ lower than those in control women $(p=0.0002-0.03)$, despite the fact that percentage body fat was almost identical in the two groups of women. Fat cell volume was directly proportional to lipolysis in obese subjects, both before and after weight reduction, and in control subjects. Insulin-induced antilipolysis and lipogenesis were completely normalised after weight reduction.
\end{abstract}

\author{
P. Löfgren · J. Hoffstedt · P. Arner \\ Department of Medicine, \\ Karolinska Institute, \\ Stockholm, Sweden \\ E. Näslund \\ Division of Surgery, \\ Karolinska Institute at Danderyd Hospital, \\ Stockholm, Sweden \\ M. Wirén \\ Department of Surgery, \\ Karolinska Institute, \\ Stockholm, Sweden \\ P. Arner $(\square)$ \\ Department of Medicine, \\ Karolinska Institute, \\ Huddinge University Hospital, \\ 14186 Huddinge, Sweden \\ e-mail: peter.arner@medhs.ki.se \\ Tel.: +46-8-58582342 \\ Fax: $+46-8-58582407$
}

Conclusions/interpretation: Body-weight-reduced obese women had low basal and catecholamine-stimulated adipocyte lipolysis, presumably due to adipose tissue hyperplasia. This could make an important contribution to body weight gain following weight loss. Adipocyte insulin resistance is secondary to obesity.

Keywords Fat cell size - Lipogenesis - Lipolysis · Post-obese - Women

Abbreviations ADA: adenosine deaminase - dcAMP: dibutyryl cyclic AMP - DEXA: dual-energy X-ray absorptiometry - HOMA: homeostasis model assessment . HSL: hormone-sensitive lipase $\cdot \mathrm{pD} 2$ : the negative log of half-maximal effective concentration

\section{Introduction}

Obesity is a major risk factor for diabetes mellitus. The excess accumulation of adipose tissue in obesity is characterised by combined hyperplasia (too many fat cells) and hypertrophy (fat cells that are too large) [1]. Insulin and catecholamines are major hormonal regulators of fat cell metabolism in man. It is well established that the actions of these hormones on fat cells are altered in obesity [2-4]. Insulin stimulates glucose uptake, as well as lipid synthesis from glucose (lipogenesis), and inhibits hydrolysis of triglycerides to glycerol and NEFAs (lipolysis). In obesity, the ability of insulin to stimulate glucose transport and lipogenesis and to induce the antilipolytic effect in human fat cells is blunted [2]. This adipose insulin resistance is related to metabolic disturbances in obese subjects, particularly to elevated circulating NEFA levels [5].

Catecholamines stimulate lipolysis via $\beta_{1^{-}}, \beta_{2^{-}}$and $\beta_{3^{-}}$ adrenoreceptors, but have also inhibitory effects on lipolysis that are mediated via $\alpha_{2}$-adrenoreceptors [6]. The lipolytic $\beta$-effect usually predominates. It is well established from both in vivo and in vitro studies that the lipolytic action of catecholamines is attenuated in the 
subcutaneous adipose tissue of obese subjects (for reviews see $[2,7])$. This catecholamine resistance has been linked to increased $\alpha_{2}$-adrenoreceptor action [8], decreased $\beta_{2^{-}}$ adrenoreceptor expression and action [9], and decreased maximum effect of catecholamines due to low expression of the gene encoding hormone-sensitive lipase (HSL) [10], the enzyme that catalyses the final rate-limiting step in lipolysis [11].

Human fat cells have a spontaneous metabolic activity. The basal rate of lipolysis is increased in the adipocytes of obese subjects (for reviews see $[3,4]$ ), and this is, at least partly, responsible for the increase in the circulating NEFA levels observed in these individuals.

Many of the adipocyte abnormalities associated with obesity improve after weight loss [12-15]. Fat cell size decreases, as does basal lipolysis. Insulin and catecholamine actions are improved. However, it is not known if these actions completely return to normal. A full normalisation would suggest that the abnormalities are secondary to obesity. However, incomplete normalisation would suggest primary defects in adipocyte function that cannot be cured by weight loss. Studies in first-degree relatives of obese subjects have demonstrated impaired lipolytic function of fat cells, which could mean that primary adipocyte lipolysis defects are present in obesity $[16,17]$.

This prospective study was undertaken to elucidate whether long-term weight reduction in obesity leads to complete or incomplete improvement of basal and hormonally induced lipid metabolism in human subcutaneous fat cells.

\section{Subjects and methods}

This study was designed in 1997 as a prospective long-term case-control study of obese women before and after they had reached a new steady-state BMI following weightreduction therapy. During 1998-2002 we recruited 25 obese (otherwise healthy) women aged $30-50$ years with a BMI of $31-50 \mathrm{~kg} / \mathrm{m}^{2}$ for studies on fat cell metabolism (lipolysis and lipogenesis). The women were to undergo non-pharmacological weight-reduction therapy and are defined as cases. All cases were subjected either to adjustable vertical gastric banding $(n=18)$ or to lifestyle modification (increased motivation, altered eating habits, increased exercise and regular follow-up) $(n=7)$. The lifestyle group was followed-up at 3, 6, 9 and 12 months. Once body weight was stable $(< \pm 1 \mathrm{~kg}$ [self-reported] for 1 month), these cases underwent a second examination. The subjects undergoing gastric banding were followed annually until body weight had reached a nadir and was stable $(< \pm 1 \mathrm{~kg}$ [self-reported] for at least 3 months) before being re-examined. All cases were healthy except for obesity and none was on continuous medication; three women were menopausal; none was completely sedentary or involved in athletics.

As soon as the timing of the second examination of a case was decided upon, a control subject was selected for each case. The control was closely matched for the BMI and age of the case at the second examination. The controls were selected from an ongoing study of the regulation of human adipose tissue function in healthy subjects with large inter-individual variations in BMI. From 1997, when recruitment started, we recruited 260 control subjects. None of the controls had undergone a notable weight change (self-reported) in the 6 months before the examination. The non-obese controls had never had a BMI $>30 \mathrm{~kg} / \mathrm{m}^{2}$ according to their self-reported maximum body weight. Thus, none of them was post-obese. When selecting the control subject, the investigator in charge of the selection (P. Löfgren) only had access to data on BMI and age. The selected controls were 15 women who were obese (BMI $30-50 \mathrm{~kg} / \mathrm{m}^{2}$, age $28-53$ years) and ten women who were non-obese (BMI $21-29 \mathrm{~kg} / \mathrm{m}^{2}$, age $29-55$ years). None of the controls were on continuous pharmacotherapy. Three were postmenopausal. None was completely sedentary or involved in athletics. The hospital's ethics committee approved the study. The study was explained to each subject and informed consent was obtained. Twenty-one of the obese women and their 21 controls also underwent examination of circulating leptin and adipose leptin production (unpublished results).

Experimental protocol The subjects came to the laboratory at 07:00-08:00 hours after an overnight fast. Height, weight, and waist and hip circumferences were measured. Percentage body fat was measured by bioimpedance (TBF 305; Tanita, Tokyo, Japan). In a methodological investigation of 38 subjects (BMI $17-41 \mathrm{~kg} / \mathrm{m}^{2}$ ) who were not included in the present study, we compared this measurement with dual-energy X-ray absorptiometry (DEXA). A strong $(r=0.92)$ relationship between the measurements was obtained. The slope was not different from 1.0, but the intercept was $+5 \%$ for DEXA ( $p=0.027$ ). The correlation was $r=0.93$ among non-obese subjects and was $r=0.86$ among obese subjects. A venous blood sample was obtained for the determination of plasma glucose, glycerol and NEFA by the hospital's routine chemistry laboratory and for the determination of plasma insulin by RIA (Pharmacia, Uppsala, Sweden). Insulin sensitivity was calculated from the homeostasis model assessment (HOMA) algorithm based on plasma glucose and plasma insulin ([plasma insulin $\times$ plasma glucose]/22.5). Thereafter, an abdominal subcutaneous adipose tissue specimen (1-2 g) was obtained under local anaesthesia using a needle biopsy technique [18].

Isolation of fat cells Isolated fat cells were prepared and isolated according to Rodbell [19]. In brief, adipocytes were separated from stroma cells by treatment in a shaking bath at $37^{\circ} \mathrm{C}$ for $60 \mathrm{~min}$ with collagenase $(0.5 \mathrm{mg} / \mathrm{l})$ in $5 \mathrm{ml}$ Krebs-Ringer phosphate buffer ( $\mathrm{pH}$ 7.4) with purified BSA (40 g/l). Adipocyte suspensions were then rinsed three times in collagenase-free buffer using nylon filters. Fat cell sizes were measured by direct microscopy and the mean adipocyte diameter was calculated from measurements of 100 cells. Because adipocytes have $95 \%$ lipid content and are spherical in shape, volume and 
weight can be estimated from the diameter [20]. The total lipid weight of the incubated fat cells was determined after organic extraction. The number of fat cells incubated was determined by dividing total lipid weight of incubated fat cells by the mean fat cell weight.

Lipolysis experiments The lipolysis assay has previously been described in detail [21]. In brief, a diluted suspension of isolated fat cells (about 5,000-10,000 cells $/ \mathrm{ml}$ ) was incubated for $2 \mathrm{~h}$ in duplicate samples with air as the gas phase at $37^{\circ} \mathrm{C}$ in Krebs-Ringer phosphate buffer (pH 7.4) supplemented with glucose $(8.6 \mu \mathrm{mol} / \mathrm{ml})$, ascorbic acid $(0.1 \mathrm{mg} / \mathrm{ml})$ and BSA $(20 \mathrm{mg} / \mathrm{ml})$ in the absence (basal) or presence of increasing concentrations of different stimulators or inhibitors of lipolysis. The latter included noradrenaline (a non-selective $\beta$ - and $\alpha_{2}$-adrenoreceptor agonist), isoprenaline (a non-selective $\beta$-adrenoreceptor agonist), dobutamine (a selective $\beta_{1}$-adrenoreceptor agonist), terbutaline (a selective $\beta_{1}$-adrenoreceptor agonist), clonidine (a selective $\alpha_{2}$-adrenoreceptor agonist), forskolin (which stimulates adenylyl cyclase), dibutyryl cyclic AMP (dcAMP; phosphodiesterase resistant) and insulin. In the experiments with insulin and clonidine, the incubation buffer was supplemented with adenosine deaminase $(\mathrm{ADA} ; 1 \mathrm{U} / \mathrm{ml})$ in order to eliminate traces of adenosine, as this substance may interfere with the antilipolytic effects that are mediated through $\alpha_{2}$-adrenergic receptors and insulin in the present incubation system. On average, ADA augmented basal glycerol release by $72 \pm$ $59 \%$ (mean $\pm \mathrm{SD} ; p<0.0001)$ in this study. 8-Bromo-cyclic AMP ( $1 \mathrm{mmol} / \mathrm{l}$, phosphodiesterase non-resistant cyclic AMP analogue) was added in the insulin experiments in order to magnify the antilipolytic effect of insulin, an effect that is mediated by phosphodiesterase 3 [22]. In methodological experiments on human subcutaneous adipose tissue, basal glycerol release from tissue fragments and from isolated fat cells showed a linear relationship $(n=251, r=0.59, p<0.0001)$.
After the incubation, an aliquot of the medium was removed and glycerol (lipolysis index) was analysed using a bioluminescence method [21]. All agents caused a concentration-dependent stimulation or inhibition of lipolysis that reached a plateau at the highest concentrations of agonist in each individual experiment. The rate of lipolysis was expressed as $\mu \mathrm{mol}$ glycerol per $10^{7}$ cells per $2 \mathrm{~h}$. We calculated the rate of glycerol release at the maximum effective concentration for each of the lipolytic or antilipolytic agents used (maximum action). The sensitivity of the adipocytes to different agents is expressed in terms of $\mathrm{pD}_{2}=-\log \left(\mathrm{EC}_{50}\right)$, where $\mathrm{EC}_{50}$ is the concentration (in $\mathrm{mol} / \mathrm{l}$ ) of agonist or antagonist that produces a halfmaximum effect, and was calculated from logistic conversion of the dose-response curves as described previously [23]. For isoprenaline and noradrenaline (norepinephrine) only, maximum effective concentrations were used; consequently, no $\mathrm{pD}_{2}$ calculations were made.

Lipogenesis experiments The method is described in detail elsewhere [24]. In brief, isolated fat cells were incubated at a concentration of $2 \%(\mathrm{v} / \mathrm{v})$ in Krebs-Ringer phosphate buffer $(\mathrm{pH} 7.4)$ containing albumin $(40 \mathrm{mg} / \mathrm{ml}),\left[3-{ }^{3} \mathrm{H}\right]$ glucose $\left(5 \times 10^{5} \mathrm{dpm} / \mathrm{ml}\right)$, unlabelled glucose $(1 \mu \mathrm{mol} / \mathrm{l})$ and varying concentrations of human insulin $(0-70 \mathrm{nmol} /$ 1). The incubations were conducted for $2 \mathrm{~h}$ at $37^{\circ} \mathrm{C}$ with air as the gas phase. Incubations were stopped by rapidly chilling the incubation vials to $4^{\circ} \mathrm{C}$. Thereafter, the incorporation of radiolabelled glucose into adipocyte lipids was determined. The incorporation of radiolabelled glucose into lipids (i.e. lipogenesis) reflects glucose transport since, at micromolar glucose concentrations, glucose transport is the rate-limiting step for lipogenesis in human fat cells [24]. Lipogenesis was expressed as the amount of glucose incorporated either per lipid weight of fat cells or per fat cell number, as described previously [24]. The sensitivity of the adipocytes to insulin was measured $\left(\mathrm{pD}_{2}\right)$ as well as the maximum action (respon-

Table 1 Characteristics of obese women before and after body weight reduction and their BMI- and age-matched controls

\begin{tabular}{|c|c|c|c|c|c|}
\hline & \multirow{2}{*}{$\begin{array}{l}\text { Cases before weight loss } \\
(n=25)\end{array}$} & \multirow{2}{*}{$\begin{array}{l}\text { Cases after weight loss } \\
(n=25)\end{array}$} & \multirow{2}{*}{$\begin{array}{l}\text { Controls } \\
(n=25)\end{array}$} & \multicolumn{2}{|l|}{$p$ value } \\
\hline & & & & Before vs after & After vs control \\
\hline Age (years) & $38.8 \pm 8.9$ & $41.4 \pm 8.8$ & $42.3 \pm 8.4$ & $<0.0001$ & 0.97 \\
\hline BMI $\left(\mathrm{kg} / \mathrm{m}^{2}\right)$ & $42.6 \pm 6.0$ & $32.5 \pm 7.0$ & $32.3 \pm 7.1$ & $<0.0001$ & 0.97 \\
\hline Body fat (\%) & $61.9 \pm 8.3$ & $45.1 \pm 7.2$ & $46.9 \pm 11.0$ & $<0.0001$ & 0.61 \\
\hline Waist circumference $(\mathrm{cm})$ & $123.2 \pm 13.5$ & $102.6 \pm 14.3$ & $101.8 \pm 16.1$ & $<0.0001$ & 0.82 \\
\hline Hip circumference (cm) & $130.7 \pm 11.0$ & $112 \pm 14.0$ & $112.1 \pm 13.0$ & $<0.0001$ & 0.81 \\
\hline Plasma insulin (pmol/1) & $20.1 \pm 1.9$ & $8.8 \pm 7.3$ & $8.7 \pm 5.9$ & $<0.0001$ & 0.92 \\
\hline Plasma glucose $(\mathrm{mmol} / \mathrm{l})$ & $6.0 \pm 2.0$ & $5.2 \pm 1.1$ & $5.3 \pm 0.5$ & 0.001 & 0.62 \\
\hline HOMA index & $5.7 \pm 5.3$ & $2.2 \pm 2.4$ & $2.3 \pm 3.0$ & $<0.0001$ & 0.6 \\
\hline Fat cell volume (pl) & $830 \pm 121$ & $523 \pm 191$ & $716 \pm 132$ & $<0.0001$ & 0.0002 \\
\hline Plasma glycerol $(\mu \mathrm{mol} / \mathrm{l})$ & $122.7 \pm 52$ & $90.5 \pm 38$ & $82.4 \pm 36$ & 0.12 & 0.33 \\
\hline Plasma NEFA (nmol/1) & $0.79 \pm 0.24$ & $0.65 \pm 0.24$ & $0.63 \pm 0.21$ & 0.02 & 0.68 \\
\hline
\end{tabular}

Values are presented as means \pm SD. Statistical comparison was made using the paired (before vs after) and unpaired (after vs control) Student's $t$-test 
siveness), as described for lipolysis (above).

Materials BSA (fraction V, lot 63F-0748), Clostridium histolyticum collagenase type I, forskolin, dcAMP, and glycerol kinase from Escherichia coli (G4509) were obtained from Sigma (St Louis, MO, USA). Isoprenaline came from Hässle (Mölndal, Sweden). ATP-monitoring reagent containing firefly luciferase came from LKB Wallac (Turku, Finland). All other chemicals were of the highest grade of purity commercially available.
Statistical analysis Values are presented as means \pm SD. They were compared using the Student's paired $t$-test in cases before vs after weight reduction and, unless otherwise stated, by the Student's unpaired $t$-test in cases after weight reduction vs controls. It is, however, also valid to use the paired $t$-test in a case-control study such as this one, as there is one predefined control for each case (discussed in [25]). A $p$ value of less than 0.05 was considered significant.

Table 2 Lipolysis and lipogenesis of isolated subcutaneous fat cells from obese women before and after weight reduction, and their ageand BMI-matched controls

$\begin{array}{llll}\text { Subjects } & & p \text { value } & \\ \begin{array}{l}\text { Cases before weight loss } \\ (n=25)\end{array} & \begin{array}{l}\text { Cases after weight loss } \\ (n=25)\end{array} & \begin{array}{l}\text { Controls } \\ (n=25)\end{array}\end{array}$

\begin{tabular}{|c|c|c|c|c|c|}
\hline \multicolumn{6}{|l|}{ Lipolysis } \\
\hline Basal & $13.0 \pm 8.3$ & $4.6 \pm 3.6$ & $7.4 \pm 4.1$ & 0.0002 & 0.01 \\
\hline \multicolumn{6}{|l|}{ Noradrenaline } \\
\hline Maximum & $27.9 \pm 14.0$ & $13.9 \pm 6.3$ & $19.8 \pm 7.2$ & 0.05 & 0.01 \\
\hline \multicolumn{6}{|l|}{ Isoprenaline } \\
\hline Maximum & $43.6 \pm 21.4$ & $22.7 \pm 11.3$ & $29.9 \pm 10.0$ & 0.0006 & 0.03 \\
\hline Maximum & $35.7 \pm 18.0$ & $20.0 \pm 10.3$ & $26.8 \pm 9.3$ & 0.02 & 0.02 \\
\hline Responsiveness & $23.6 \pm 14.5$ & $15.7 \pm 9.3$ & $18.9 \pm 8.1$ & 0.05 & 0.35 \\
\hline $\mathrm{pD}_{2}$ & $7.2 \pm 0.7$ & $7.5 \pm 0.6$ & $7.4 \pm 0.5$ & 0.2 & 0.5 \\
\hline \multicolumn{6}{|l|}{ Terbutaline } \\
\hline Maximum & $38.3 \pm 19.3$ & $20.9 \pm 9.8$ & $28.8 \pm 9.6$ & 0.0009 & 0.006 \\
\hline Responsiveness & $29.8 \pm 18.3$ & $17.5 \pm 8.9$ & $21.2 \pm 8.0$ & 0.03 & 0.15 \\
\hline \multicolumn{6}{|l|}{ dcAMP } \\
\hline Maximum & $38.2 \pm 20.6$ & $21.2 \pm 8.4$ & $27.0 \pm 8.8$ & 0.001 & 0.01 \\
\hline Responsiveness & $25.2 \pm 14.8$ & $16.5 \pm 6.1$ & $19.6 \pm 7.1$ & 0.01 & 0.06 \\
\hline \multicolumn{6}{|l|}{ Clonidine + ADA } \\
\hline Basal & $16.6 \pm 10.0$ & $8.3 \pm 5.4$ & $10.4 \pm 5.0$ & 0.002 & 0.2 \\
\hline Minimum & $3.5 \pm 2.7$ & $1.6 \pm 1.0$ & $2.2 \pm 1.1$ & 0.007 & 0.03 \\
\hline Responsiveness & $13.1 \pm 7.9$ & $6.7 \pm 4.7$ & $8.1 \pm 4.5$ & 0.03 & 0.41 \\
\hline $\mathrm{pD}_{2}$ & $10.0 \pm 1.3$ & $9.8 \pm 0.9$ & $9.8 \pm 1.0$ & 0.7 & 0.9 \\
\hline \multicolumn{6}{|c|}{ 8-Bromo-cyclic AMP + insulin } \\
\hline Maximum & $2.8 \pm 1.8$ & $6.8 \pm 7.7$ & $6.4 \pm 4.9$ & 0.0006 & 0.9 \\
\hline Responsiveness & $1.67 \pm 1.4$ & $4.2 \pm 5.6$ & $3.5 \pm 2.6$ & 0.04 & 0.6 \\
\hline $\mathrm{pD}_{2}$ & $11.8 \pm 1.6$ & $12.6 \pm 1.3$ & $12.9 \pm 1.6$ & 0.04 & 0.5 \\
\hline
\end{tabular}




\section{Results}

In all cases there was a decrease in BMI following treatment, from about 43 to $32 \mathrm{~kg} / \mathrm{m}^{2}$. Thus, the cases were, on average, still obese after weight reduction. The second biopsy was performed at $2.7 \pm 1$ year in those treated with gastric banding and after 1 year in the lifestyle-modification group. The clinical data before and after treatment of cases and their controls are shown in Table 1. Fasting plasma glucose, plasma insulin and the HOMA index were significantly lower after weight reduction than before $(p<0.004)$. The same was true for percentage body fat, and for waist and hip circumference. When weight-reduced subjects and controls were compared, fat cell volume was $27 \%$ lower $(p<0.0002)$ in cases than in controls. No other clinical variables differed significantly between controls and cases.

The group results for lipolysis and lipogenesis are presented in Table 2. In the obese subjects, weight reduction significantly decreased basal lipolysis and maximum lipolysis induced by noradrenaline, isoprenaline, dobutamine, terbutaline, forskolin, dcAMP or clonidine. However, basal lipolysis and maximum values for lipolysis induced by the different lipolytic agents and minimum values for clonidine were $20-40 \%$ lower in cases after weight loss than in the controls $(p=0.009-0.03)$. Sensitivity to the $\beta_{2}$-agonist terbutaline was significantly increased after therapy ( $p=0.02)$ to a similar value to that in controls. No change in sensitivity $\left(\mathrm{pD}_{2}\right)$ was seen for the other agents used and values were similar to those in controls. The maximum ability of insulin to inhibit lipolysis and anti-lipolytic sensitivity $\left(\mathrm{pD}_{2}\right)$ were significantly improved in the cases after weight loss. There was, on the other hand, no significant difference in insulin action on lipolysis between controls and cases $(p=0.6-0.8)$.

As regards lipogenesis, increases in insulin sensitivity, maximal insulin action and basal lipogenesis were observed after weight reduction $(p=0.04-0.0006)$. There were no differences in lipogenesis between weight-reduced obese subjects and their matched controls $(p=0.6-0.9)$.

Extended observations were carried out on a subset of cases $(n=9)$ to determine whether lipolysis was stable after weight reduction. Adipose tissue biopsies were performed at $0,2.8 \pm 0.7$ and $3.9 \pm 0.6$ years after intervention. Figure 1 shows BMI, basal lipolysis and dcAMP-stimulated lipolysis. These variables decreased markedly between 0 and 2 years and remained constant thereafter. Similar results were obtained with other lipolytic agents used (data not shown).

We performed a subgroup analysis on those obese subjects who reached the non-obese state $\left(B M I<30 \mathrm{~kg} / \mathrm{m}^{2}\right)$ after treatment ( $n=10$; referred to below as the post-obese) and on their controls. In general, the results from this subgroup analysis were not different from the results obtained using the whole sample. BMI, percentage body fat, waist and hip circumference, plasma glucose, plasma glycerol, plasma NEFA, plasma insulin and the HOMA index decreased $(p=0.003-0.0001)$ following weight reduction to values (not shown in table) similar to those for the control group ( $p=0.4-0.93)$. The post-obese had, on
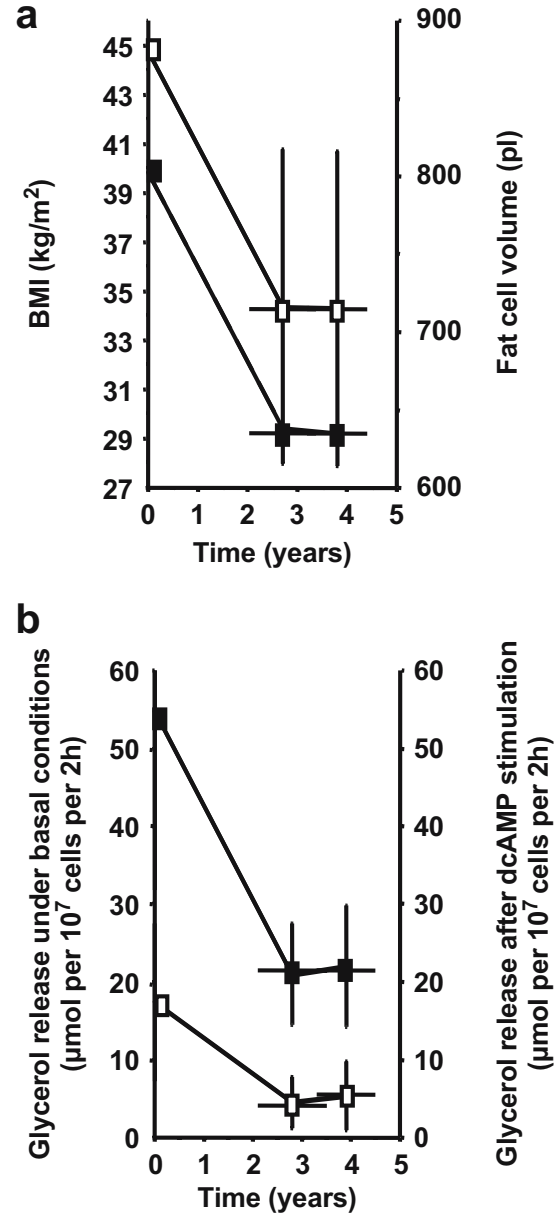

Fig. 1 BMI (open squares) and fat cell volume (filled squares) (a) and basal lipolysis (open squares) and dcAMP-stimulated lipolysis (filled squares) (b) in a subset of cases $(n=9)$ that was examined three times

average, near-normal weight (BMI $25.5 \pm 2.6 \mathrm{~kg} / \mathrm{m}^{2}$ ). Mean fat cell volume decreased from $827 \pm 148 \mathrm{pl}$ in the obese state to $349 \pm 165 \mathrm{pl}$ in the post-obese state $(p=0.0001)$, which was significantly lower than fat cell volume in the control group $(607 \pm 120 \mathrm{pl} ; p=0.0008)$.

The same pattern of treatment response in terms of lipolysis and lipogenesis variables was seen in the postobese group as was observed in the whole sample (Table 3). However, differences in lipolysis between controls and post-obese subjects were more pronounced than those between controls and the cases as a whole. Basal lipolysis was almost $60 \%$ lower in the post-obese state, and maximal isoprenaline lipolysis was about $50 \%$ lower among the post-obese than among their controls. The antilipolytic effects of insulin and lipogenesis were completely normalised in the post-obese.

To test if differences in maximum lipolysis between subjects after intervention and controls merely reflect changes in basal lipolysis, we made calculations with basal lipolysis subtracted (responsiveness). Lipolytic responsiveness did not differ significantly between cases after intervention and controls (see Table 2). However, analys- 
Table 3 Lipolysis and lipogenesis in isolated subcutaneous fat cells in obese women reaching BMI $<30 \mathrm{~kg} / \mathrm{m}^{2}(n=10)$ before and after weight reduction and their age- and BMI-matched controls (see legends to Tables 1 and 2 for further details)

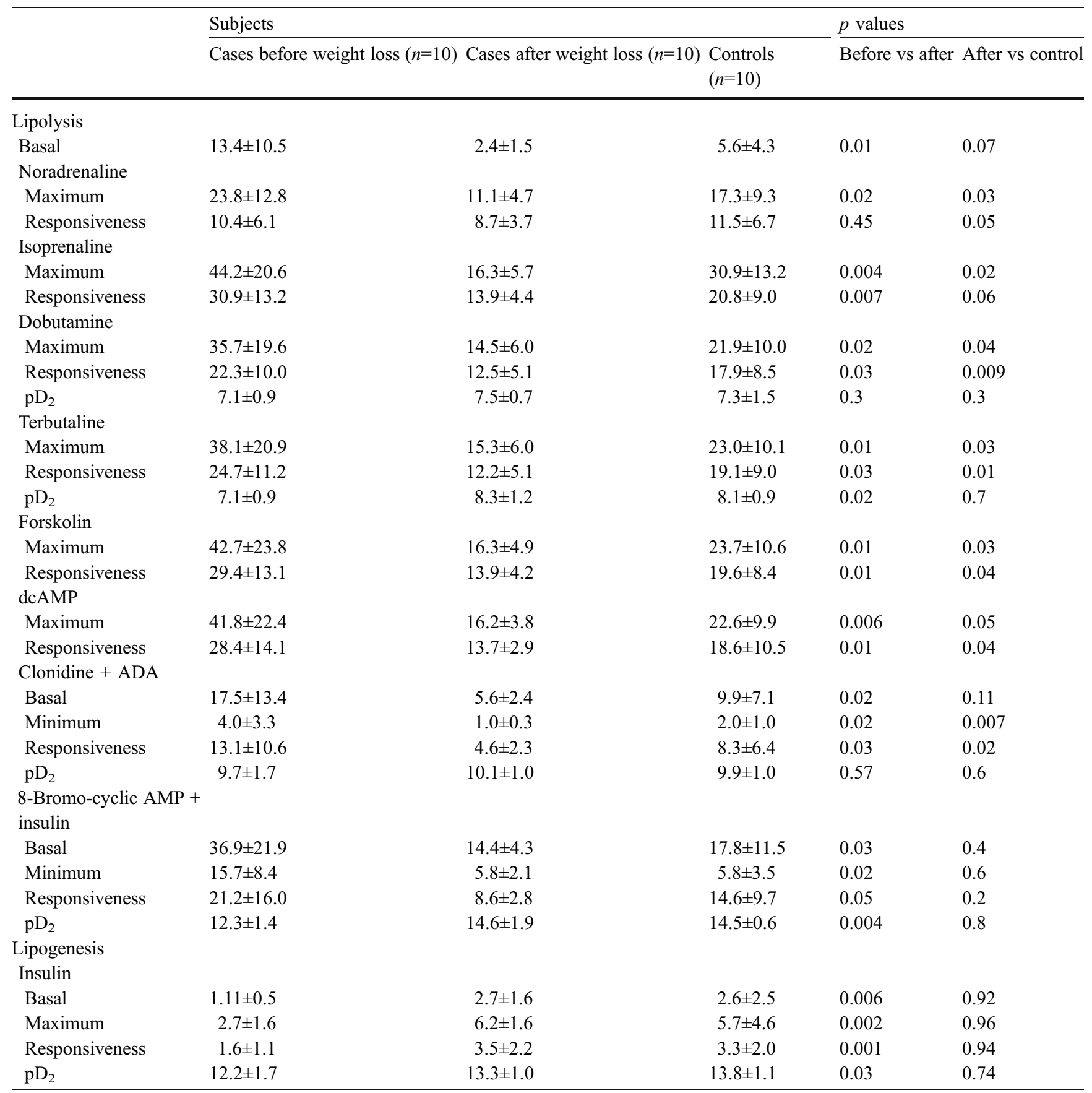

ing responsiveness in the post-obese group (see Table 3) revealed a $25-40 \%$ lower responsiveness in post-obese subjects compared with controls $(p=0.009-0.05)$. There were no differences between the cases (post-weight loss) and their controls when basal lipogenesis was subtracted from maximum lipogenesis. When expressing lipolysis as percentage change from basal levels, no statistical difference was seen between post-obese subjects and controls. When correcting lipolysis values for cell surface area, there was no difference in basal and stimulated lipolysis between obese subjects before and after intervention or between obese subjects after intervention and controls (data not shown). The decrease in lipolytic rate was related to the decrease in percentage body fat: $15-30 \%$ of the reduction in lipolytic rates could be attributed to reduction of percentage body fat (adjusted $R^{2}=0.15-0.30, p=0.01-0.05$ ).

We also performed other subgroup analyses by excluding the postmenopausal cases and controls or by excluding the lifestyle-intervention group and their controls. The results for these subgroups did not differ in any important aspect from the data recorded for the whole sample. We also used the paired $t$-test when comparing weight-reduced 
Fig. 2 The mean basal (a) and maximum-stimulated forskolin (b), dcAMP (c) and isoprenaline (d) lipolysis in relation to fat cell volume in obese subjects before and after weight reduction and in their controls are depicted. Filled squares, obese subjects before treatment; open squares, the same subjects after weight reduction; open circles, controls
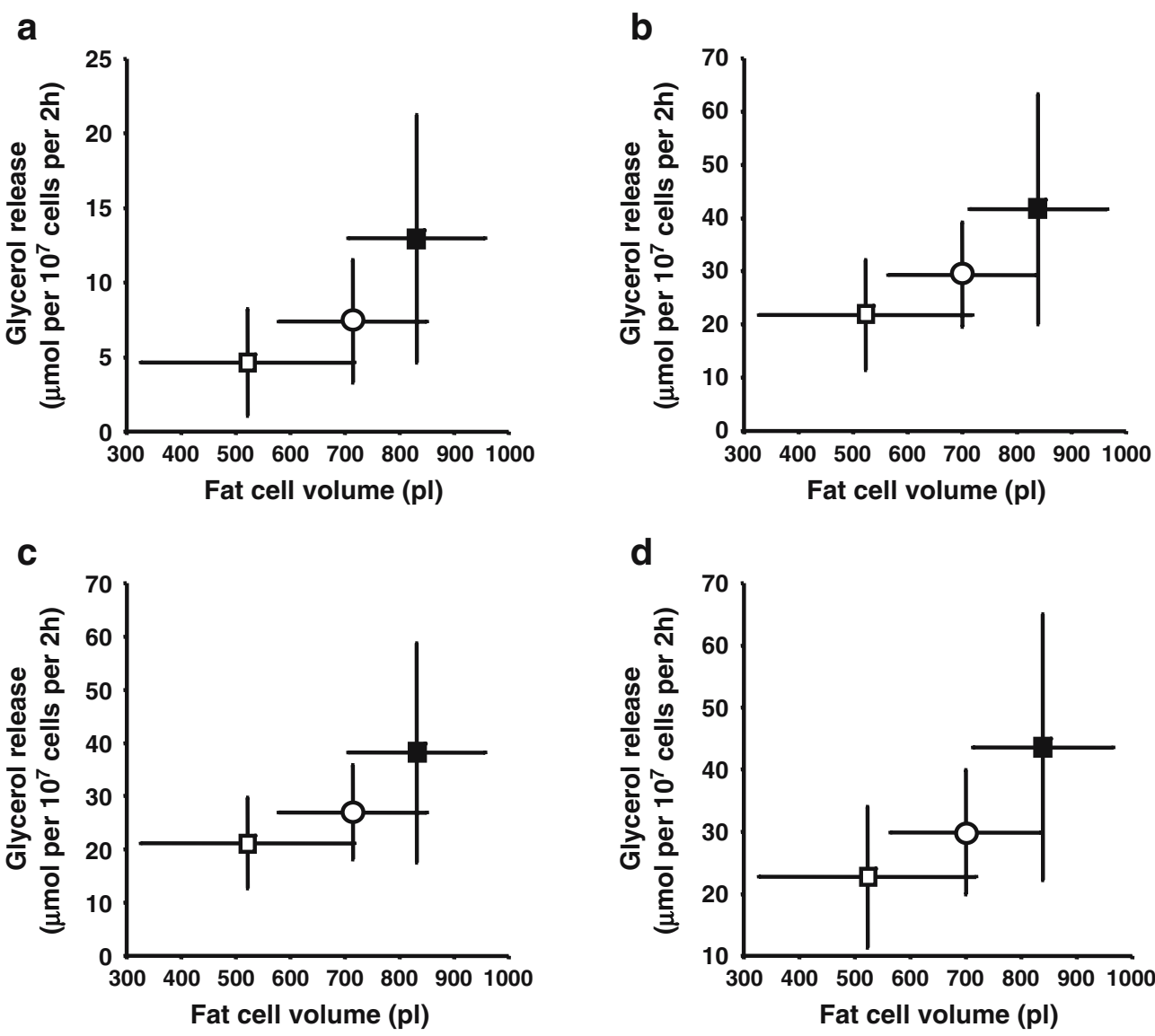

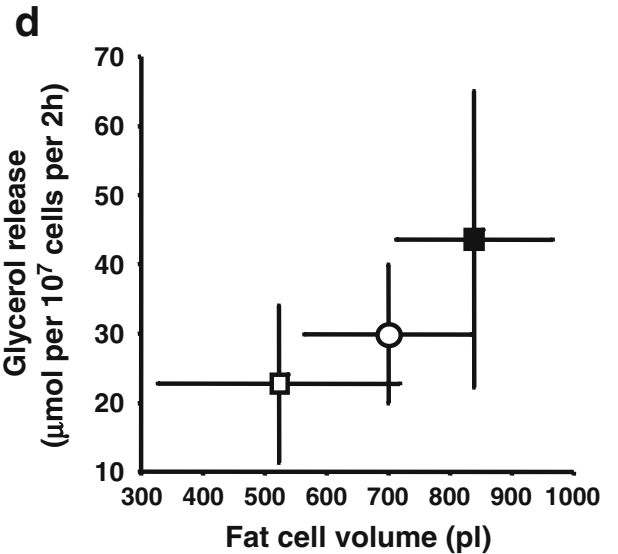

subjects with controls. The results were the same as those obtained with the unpaired $t$-test.

Figure 2 shows the relationship between fat cell size and lipolysis in the cases, both before and after weight reduction, and in the controls. There is an apparent linear relationship between mean values for fat cell volume on the one hand and basal, isoprenaline, forskoline and dcAMPinduced lipolysis on the other hand.

\section{Discussion}

In the present investigation we have prospectively examined if abnormalities in the metabolic regulation of fat cells among obese subjects are partially or fully normalised following weight reduction. We only examined women. Therefore, we do not know if our findings also apply to men. Previous studies have shown a different pattern for the response of adipocyte lipolysis to weight reduction when men and women were compared [15, 26]. In previous studies of weight reduction, weight-reduced obese subjects have been compared with much leaner controls, with up to $10 \mathrm{~kg} / \mathrm{m}^{2}$ difference in BMI. Such studies cannot show if a full, incomplete or 'super normalisation' takes place following weight reduction. Our weight-reduced obese subjects had a similar BMI, percentage body fat and body fat distribution (assessed by waist and hip circumference measurements) to the control subjects. We used bioimpedance as a measure of body fat. Although this method might be less accurate for measuring body fat in obese subjects, we found it to correlate strongly with the 'gold standard', DEXA, in a methodological investigation performed on a separate population of nonobese and obese subjects. In any case, bioimpedance is accurate in our estimation of body fat among the subgroup of post-obese subjects.

Fat cell size has a great influence on the rate of lipolysis [3]. This is further supported by the fact that differences in lipolysis between groups disappear after correction for fat cell surface area. Larger cells have increased basal lipolysis. However, insulin action is also dependent on fat cell size. Large human fat cells are more resistant to insulin-induced glucose metabolism [27], and large fat cell size is an independent risk factor for the development of type 2 diabetes [28]. A prominent finding in this study was a decrease in fat cell volume below the control level in weight-reduced obese subjects. Since BMI, fat distribution and body fat content were similar in obese subjects and their controls, the results imply that adipose hyperplasia (at least in abdominal subcutaneous adipose tissue) is a major feature of weight-reduced obese subjects. At present we do not know if this is a primary defect that precedes obesity or if it appears during the development of obesity. It is less likely that hyperplasia develops as a result of weight reduction per se. In a previous study we observed that, although fat cell volume and lipolysis were reduced 
following weight reduction, they remained higher than those in controls [15]. However, those data and the present results cannot be compared, since the controls in the previous study had a BMI about $10 \mathrm{~kg} / \mathrm{m}^{2}$ lower than their weight-reduced subjects whereas our weight-reduced subjects and controls had practically the same BMI.

As regards previous studies, contrasting findings have been reported on basal and maximal lipolysis in response to weight reduction. Some reports show no change $[26,29-$ $33]$, an enhancement $[30,34,35]$ or a reduction $[15,31,36$, 37] in lipolysis after weight loss. These contradicting results may be explained by variation in study duration (study length varied from a few weeks up to several years), differences in methods used to initiate weight loss, and examination while subjects were or were not weight stable. We followed our subjects for a long time (1 year for lifestyle intervention and about 3 years for gastric banding). Our patients were definitively weight stable when examined after intervention and their lipolysis variables were also stable at the time of the second investigation, according to the results presented in Fig. 1. Therefore, our findings of lower basal and clonidine-inhibited and maximum-stimulated lipolysis in weight-reduced obese subjects are most probably valid. However, the previously described impaired $\beta_{2}$-adrenoreceptor function [9] among obese subjects is probably secondary to obesity since, in the present study, $\beta_{2}$-adrenoreceptor sensitivity was completely normalised after weight reduction. When comparing lipolysis in the whole weight-reduced group with that in their matched controls, basal and maximalstimulated lipolysis were $20-40 \%$ lower in the former than in the latter group. This might, in part, be explained by a relatively higher rate of basal lipolysis in controls than in obese subjects after intervention, since the differences are not significant after subtracting basal from maximal values (responsiveness). However, responsiveness was significantly lower in the post-obese group than in the controls, suggesting impaired maximum stimulated lipolysis. When we compared the results for the obese subjects before weight reduction with those for the cases after weight reduction and those for the controls, a linear relationship of fat cell volume with basal lipolysis as well as with stimulated lipolysis was observed between all three groups of data. Bearing in mind the strong relationship between fat cell size and lipolysis, it is probable that the low rates of lipolysis seen in the weight-reduced subjects are secondary to the 'too-small' fat cells. It is also possible that reduction of catecholamine action and improvement of insulin action could be a homeostatic mechanism to limit excess NEFA release from adipose tissue. Our data on circulating NEFAs support this view. A major problem with the treatment of obesity is the frequent regain of lost weight after antiobesity therapy. The underlying mechanisms behind this phenomenon are not known. It is tempting to speculate that the low ability to mobilise fat from adipose tissue is secondary to adipose hypercellularity and that low lipolytic activity could, at least in part, explain the frequent relapse of body weight after weight reduction in obese individuals.
The fact that weight-reduced obese subjects had normal fasting plasma glycerol and NEFAs in spite of adipocyte hyperplasia further strengthens the hypothesis of low lipolysis values per cell number in the weight-reduced state. Since we found a reduced lipolytic effect by all agents tested, including a cyclic AMP analogue, it is very likely that the reduced lipolytic rate in fat cells of postobese subjects is caused by events that occur at or near HSL in the lipolysis pathway. This notion is further supported by reports of low expression of the gene encoding adipocyte HSL in obese subjects [10] and low HSL protein production [15], and the finding of a close correlation between adipose lipolytic capacity and the amount of HSL as protein [38]. It would have been interesting to investigate HSL levels. Unfortunately, this could not be done due to lack of tissue specimens.

It is well established that insulin resistance in adipose tissue and other target organs for the hormone is present among obese subjects. On the other hand, it is not known whether these abnormalities are fully normalised following weight reduction, although overall insulin sensitivity, as measured by the hyperinsulinaemic-normoglyacaemic clamp, is normalised following bariatric surgery of obese subjects [39]. Vazquez et al. [39] examined insulinstimulated glucose metabolism in adipocytes of obese subjects following weight reduction. Improvement, but not normalisation, was observed. Our data clearly demonstrate complete normalisation of insulin inhibition of lipolysis and stimulation of lipogenesis following weight reduction. This implies that impaired insulin metabolism in adipocytes is secondary to obesity. However, since fat cell volume was lower in weight-reduced subjects than in controls, and basal and insulin-stimulated glucose did not differ between these two groups, factors other than fat cell volume per se must be of importance for insulin action in fat cells. Overall insulin sensitivity in vivo as measured by HOMA was also fully normalised after weight reduction.

The data for the whole cohort may be confounded because a large number of the controls were obese. Importantly, however, the findings relating to lipolysis, adipose cellullarity and lipogenesis were maintained when we performed a subgroup analysis of the women reaching the post-obese state compared with the never-obese controls (BMI $<30 \mathrm{~kg} / \mathrm{m}^{2}$ ). This further strengthens the idea that insulin resistance is secondary to obesity, whereas adipose hypercellularity and low adipose lipolytic rates may be primary factors in obesity.

In conclusion, adipose tissue hyperplasia (many small fat cells) is present in the weight-reduced state and probably explains the low rates of adipocyte lipolysis in this condition. However, adipocyte insulin resistance is a secondary and fully reversible phenomenon in obesity.

\section{References}

1. Prins JB, O'Rahilly S (1997) Regulation of adipose cell number in man. Clin Sci (Lond) 92:3-11 
2. Large V, Arner P (1998) Regulation of lipolysis in humans. Pathophysiological modulation in obesity, diabetes and hyperlipidaemia. Diabetes Metab 24:409-418

3. Arner P (1998) Control of lipolysis and its relevance to development of obesity in man. Diabetes Metab Rev 4:409-418

4. Caro JF, Dohm LG, Pories WJ, Sinah MK (1989) Cellular alterations in liver, skeletal muscle, and adipose tissue responsible for insulin resistance in obesity and type II diabetes. Diabetes Metab Rev 5:665-689

5. Eckel RH, Grundy SM, Zimmet PZ (2005) The metabolic syndrome. Lancet 365:1415-1428

6. LaFontan M, Berlan M (1995) Fat cell alpha 2-adrenoceptors: the regulation of fat cell function and lipolysis. Endocr Rev 16:716-738

7. Coppack SW, Jensen MD, Miles JM (1994) In vivo regulation of lipolysis in humans. J Lipid Res 35:177-193

8. Mauriege P, Despres JP, Prud'homme D et al (1991) Regional variation in adipose tissue lipolysis in lean and obese men. J Lipid Res 32:1625-1633

9. Reynisdottir S, Wahrenberg H, Carlstrom K, Rossner S, Arner P (1994) Catecholamine resistance in fat cells of women with upper body obesity due to decreased expression of beta 2adrenoceptors. Diabetologia 37:428-435

10. Large V, Reynisdottir S, Langin D et al (1999) Decreased expression and function of adipocyte hormone-sensitive lipase in subcutaneous fat cells of obese subjects. J Lipid Res 40:2059-2066

11. Holm C (2003) Molecular mechanisms regulating hormonesensitive lipase and lipolysis. Biochem Soc Trans 31:11201124

12. Nicklas BJ, Rogus EM, Berman DM, Dennis KE, Goldberg AP (2000) Responses of adipose tissue lipoprotein lipase to weight loss affect lipid levels and weight regain in women. Am J Physiol Endocrinol Metab 279:E1012-E1019

13. Dennis KE, Goldberg AP (1993) Differential effects of body fatness and body fat distribution on risk factor for cardiovascular disease in women. Impact of weight loss. Arterioscler Thromb 13:1487-1494

14. Goodpaster BH, Kelley DE, Wing RR, Meier A, Thaete FL (1999) Effects of weight loss on regional fat distribution and insulin sensitivity in obesity. Diabetes 48:839-847

15. Löfgren P, Hoffstedt J, Rydén M et al (2002) Major gender differences in the lipolytic capacity of abdominal subcutaneous fat cells in obesity observed before and after long-term weight reduction. J Clin Endocrinol Metab 87:764-771

16. Hellström L, Reynisdottir S (2000) Influence of heredity for obesity on adipocyte lipolysis in lean and obese subjects. Int $\mathrm{J}$ Obes Relat Metab Disord 24:340-344

17. Hellström L, Langin D, Reynisdottir S, Dauzats M, Arner P (1996) Adipocyte lipolysis in normal weight subjects with obesity among first-degree relatives. Diabetologia 39:921-928

18. Kolaczynski JW, Morales LM, Moore JH Jr et al (1994) A new technique for biopsy of human abdominal fat under local anaesthesia with Lidocaine. Int J Obes Relat Metab Disord 18:161-166

19. Rodbell M (1964) Metabolism of isolated fat cells. Effects of hormones on glucose metabolism and lipolysis. J Biol Chem 239:375-380

20. Hirsch J, Gallian E (1968) Methods for determination of adipose cell size and cell number in man and animals. J Lipid Res 9:110-119

21. Hellmér J, Arner P, Lundin A (1989) Automatic luminometric kinetic assay of glycerol for lipolysis studies. Anal Biochem 177:132-137
22. Lönnqvist F, Wennlund A, Arner P (1988) Antilipolytic effects of insulin and adenylate cyclase inhibitors on isolated human fat cells. Int J Obes 13:137-146

23. Östman J, Arner P, Kimura H, Wahrenberg H, Engfeldt P (1984) Influence of fasting on lipolytic response to adrenergic agonists and adrenergic receptors in subcutaneous adipocytes. Eur J Clin Invest 14:383-391

24. Arner P, Engfeldt P (1987) Fasting mediated alteration studies of insulin action on lipolysis and lipogenesis in obese women. Am J Physiol 253:193-201

25. Chen MK (1981) Paired $t$-test, negative intraclass correlations, and case-control studies. Am J Clin Nutr 34:956-959

26. Mauriege P, Imbeault P, Langin D et al (1999) Regional and gender variations in adipose tissue lipolysis in response to weight loss. J Lipid Res 40:1559-1571

27. Smith U (1970) Insulin responsiveness and lipid synthesis in human fat cells of different sizes: effect of the incubation medium. Biochim Biophys Acta 218:417-423

28. Weyer C, Foley JE, Bogardus C, Tatarinni PA, Pratley RE (2000) Enlarged subcutaneous abdominal adipocyte size, but not obesity it self, predicts type 2 diabetes independent of insulin resistance. Diabetologia 43:1498-1506

29. Hellström L, Reynisdottir S, Langin D, Rössner S, Arner P (1996) Regulation of lipolysis in fat cells of obese women during long-term hypocaloric diet. Int J Metab Disord 20:745752

30. Rozen R, Banegas E, Davilla M, Apfelbaum M (1984) Effects of a very-low-calorie diet on adrenergic responsiveness in human adipose tissue. Int J Obes 8:141-149

31. Crampes F, Marceron M, Beauville M et al (1989) Platelet alpha2-adrenoceptors and adrenergic adipose tissue responsiveness after moderate hypocaloric diet in obese subjects. Int J Obes 13:99-110

32. Presta E, Leibel RL, Hirsch J (1990) Regional changes in adrenergic receptor status during hypocaloric intake do not predict changes in adipocyte size or body shape. Metabolism 39:307-315

33. Stich V, Harant I, De Glisezinski I (1997) Adipose tissue lipolysis and hormone-sensitive lipase expression during verylow-calorie diet in female identical twins. J Clin Endocrinol Metab 82:739-744

34. Kather H, Wieland E, Fischer B, Wirth A, Schlierf G (1985) Adrenergic regulation of lipolysis in abdominal adipocytes of obese subjects during caloric restriction: reversal of catecholamine action caused by relief of endogenous inhibition. Eur J Clin Invest 15:30-37

35. Berlan M, Dang-Tran L, Lafontan M, Denard Y (1981) Influence of hypocaloric diet on alpha-adrenergic responsiveness of obese human subcutaneous adipocytes. Int J Obes $5: 145-153$

36. Smith U, Hammersten J, Björntorp P, Kral JG (1979) Regional differences and effect of weight reduction on human fat cell metabolism. Eur J Clin Invest 9:327-332

37. Reynisdottir S, Langin D, Carlstrom K, Holm C, Rossner S, Arner P (1995) Effects of weight reduction on the regulation of lipolysis and adipocytes of women with upper-body obesity. Clin Sci (Lond) 89:421-429

38. Large V, Arner P, Reynisdottir S et al (1998) Hormone sensitive lipase expression and activity in relation to lipolysis in human fat cells. J Lipid Res 39:1688-1695

39. Vazquez LA, Pazos F, Berrazueta JR et al (2005) Effects of changes in body weight and insulin resistance on inflammation and endothelial function in morbid obesity after bariatric surgery. J Clin Endocrinol Metab 90:316-322 